\title{
Asthma history predicts the risk of affective disorders and anxiety disorders
}

\author{
Wenbin Liang*, Tanya Chikritzhs \\ National Drug Research Institute, Curtin University of Technology, Perth, Australia; \\ *Corresponding Author: w.liang@curtin.edu.au
}

Received 19 December 2012; revised 17 January 2013; accepted 26 January 2013

\begin{abstract}
Background: Positive associations between asthma and a range of mental disorders have been increasingly reported in cross-sectional studies. It is important to determine whether the association between asthma and mental disorders may be causal. Objectives: We conducted a retrospective cohort study using data collected from the 2007 Australia Mental Health and Wellbeing survey (MHW) to examine whether preexisting asthma may predict the likelihood of various types of anxiety disorders and affective disorders. Design, Settings and Subjects: The 2007 MHW survey was a nationally representative household survey. Its data included 8841 Australian adults aged 18 - 85 yrs. Age at first onset of asthma and mental disorders were used to reveal the order of occurrence of asthma and mental disorders, and to define time at risk and asthma exposure. Kaplan-Meier failure function and multivariate Poisson regression models were employed in analysis. Results: Participants who had a history of asthma that lasted six months or more were at higher risk of panic disorder, obsessive compulsive disorder, posttraumatic stress disorder, bipolar disorder, mania and hypomania. The association between asthma history and risk of mental disorder subtypes differed by gender. Conclusion: The findings of this study support the hypothesis that pre-existing asthma increases the risk of a number of anxiety disorders and affective disorders. Predisposition to carbon dioxide hypersensitivity and corticosteroid therapy may partly explain the observed associations.
\end{abstract}

Keywords: Asthma; Affective Disorders; Anxiety Disorders; Primary Care

\section{INTRODUCTION}

Asthma is one of the major public health problems that affect children and adults in both industrialised and developing countries $[1,2]$. Over the last several decades, the prevalence of asthma appears to have increased continuously. Although the observed trend may be partly due to improvements in awareness, screening and diagnosis, it is believed to reflect a real increase due to increasing prevalence of environmental risk factors [1,2]. Despite the current treatment for asthma focusing on control of physiological responses to allergens and environmental factors, asthma was once considered a psychological illness $[2,3]$. In recent years the positive association between asthma and a range of mental disorders has been increasingly reported in cross-sectional studies [3-9]. Cross-sectional studies however do not typically allow the direction of causality to be determined [8]. Moreover, only a small number of prospective studies have sought to address the association between asthma and mental disorders, two of which have reported that asthma is associated with a higher risk of panic disorders $[10,11]$.

Evidence from clinical studies suggests that increasing levels of carbon dioxide [12,13] and respiratory abnormalities [14] can trigger panic disorders among those with hypersensitivity to carbon dioxide. It has also been observed that corticosteroids which are commonly prescribed to treat asthma, may increase the risk of mood disorders in a dose-response manner $[15,16]$. Understanding the associations between asthma and the risks of mental disorders has significant implications for asthma treatment and follow-up in primary care settings. The aim of our study is to conduct a retrospective cohort study using data collected from the 2007 Australian Mental Health and Wellbeing survey (MHW) to investigate whether pre-existing asthma may predict the likelyhood of anxiety disorders and affective disorders.

\section{METHOD}

This is a retrospective cohort study based on data collected from the 2007 MHW survey. The 2007 MHW survey was a nationally representative household survey. Its data included 8841 Australian adults aged 18 - 85 yrs 
[17]. Each interview collected information required for the assessment of DSM-IV and ICD-10 mental disorders using a modified version of the World Mental Health Survey Initiative version of the Composite International Diagnostic Interview (WMH-CIDI 3.0). Interviews were conducted by trained interviewers [18]. In this study DSM-IV diagnoses were used. The diagnoses covered in the 2007 MHW survey included: 1) affective disorders, major depression, dysthymia, bipolar affective disorder; 2) anxiety disorders, agoraphobia, social phobia, panic disorder, generalized anxiety disorder, obsessive compulsive disorder, post-traumatic stress disorder [18]. Details of measurements and interviews have been described in the summary of results produced by the Australia Bureau of Statistics [18] and by Slade et al. [17].

The 2007 MHW survey estimated the age of first onset for mental disorders based on the respondent's recalled age for the first time experience of an episode [18]. The interview also collected information on the age at diagnosis of asthma. The participants were asked whether they have ever been informed by a doctor or a nurse that they have asthma. If the answer was "yes" then the participants were further asked to report: 1) their age at that time and 2) whether their asthma had lasted for six months or more [18]. In the current study, age at first onset of asthma and mental disorders were used to reveal the order of occurrence of asthma and mental disorders, and to define time at risk and asthma exposure. The analytical strategy was similar to that described by Kessler et al. [19]. Kessler and colleagues successfully used age at first onset drawn from a national mental health survey to define the order of exposure and outcomes in a retrospective cohort study [19].

\section{Data Analysis}

Kaplan-Meier failure function graphs by gender were used to describe the difference in cumulative risk of anxiety disorders between participants with a previous diagnosis of asthma that lasted for six months or more and those without a previous diagnosis of asthma. The same analysis was repeated for affective disorders. Survival time was defined as between birth and the time of the survey or the onset of an anxiety disorder or an affective disorder, whichever came first. The difference in survival function between participants with asthma and those without were tested by log-rank test which adjusted for gender as well as performing separately for each gender. Log-rank tests were repeated for subtypes of mental disorders. Subtypes of mental disorders which indicated a significant difference in the log-rank tests were further investigated with multivariate Poisson regression models. Where the effect of asthma appeared to vary by gender in the log-rank tests and Kaplan-Meier failure function graphs (see Appendix materials), multivariate Poisson re- gression models were further performed for each gender.

Because anxiety disorders and affective disorders influence the risk of each other, multivariate analysis was also used to estimate the adjusted effects of different types of mental disorders. In the Poisson models, the retrospective cohort data was converted from a per-participant unit of measurement to a per-person-time unit of measurement. Each unit of observation was one person-year at risk, which was denoted by the participant from whom the event was observed and the age of the participant at the time when the event was observed (similar to age at different follow-up periods in prospective cohort study). A similar analytical strategy was used by Kessler et al. (1997) to predict alcohol dependence [19]. The analysis period began at birth and ended when an event was observed or the time of the survey whichever came first (i.e. in the same manner as if in a prospective cohort study). The Poisson regression model included three categories for asthma exposure: 1 ) without a previous diagnosis of asthma; 2) with a previous diagnosis of asthma that lasted at least six months; and 3) with a previous diagnosis of asthma that lasted for less than six months. The models also controlled for gender, age at survey (adjusting for cohort effects), age when person-years at risk were observed, whether the participant had started smoking daily, and pre-existence of affective disorder (when the outcome was an anxiety disorder) or pre-existence of anxiety disorder (when the outcome was an affective disorder).

\section{RESULTS}

Among females, the cumulative risk of anxiety disorders was significantly higher for those who had a history of asthma that lasted for six months or more compared to those without a previous history of asthma. In contrast, the cumulative risk of anxiety disorders was similar among males who had a history of asthma that lasted for six months or more when compared to those without a previous history of asthma (Figure 1 and Table 1).

As shown in Figure 2, the cumulative risk of affective disorders was higher among those who had a history of asthma that lasted for six months or more compared to those without a previous history of asthma for each gender. However, the survival functions were only significantly different when the subsamples of both genders were combined (Table 1).

When subtypes of mental disorders were investigated separately, the cumulative risk of panic disorders, obsessive compulsive disorder, post-traumatic stress disorder, bipolar disorders, and mania and hypomania disorders were significantly higher among subjects with a previous history of asthma that lasted 6 months or more compared to those without a history of asthma for the whole sample. The cumulative risk of dysthymia was found to be sig- 
Table 1. Gender-specific log-rank tests for survival functions of anxiety disorders and affective disorders and previous asthma exposure.

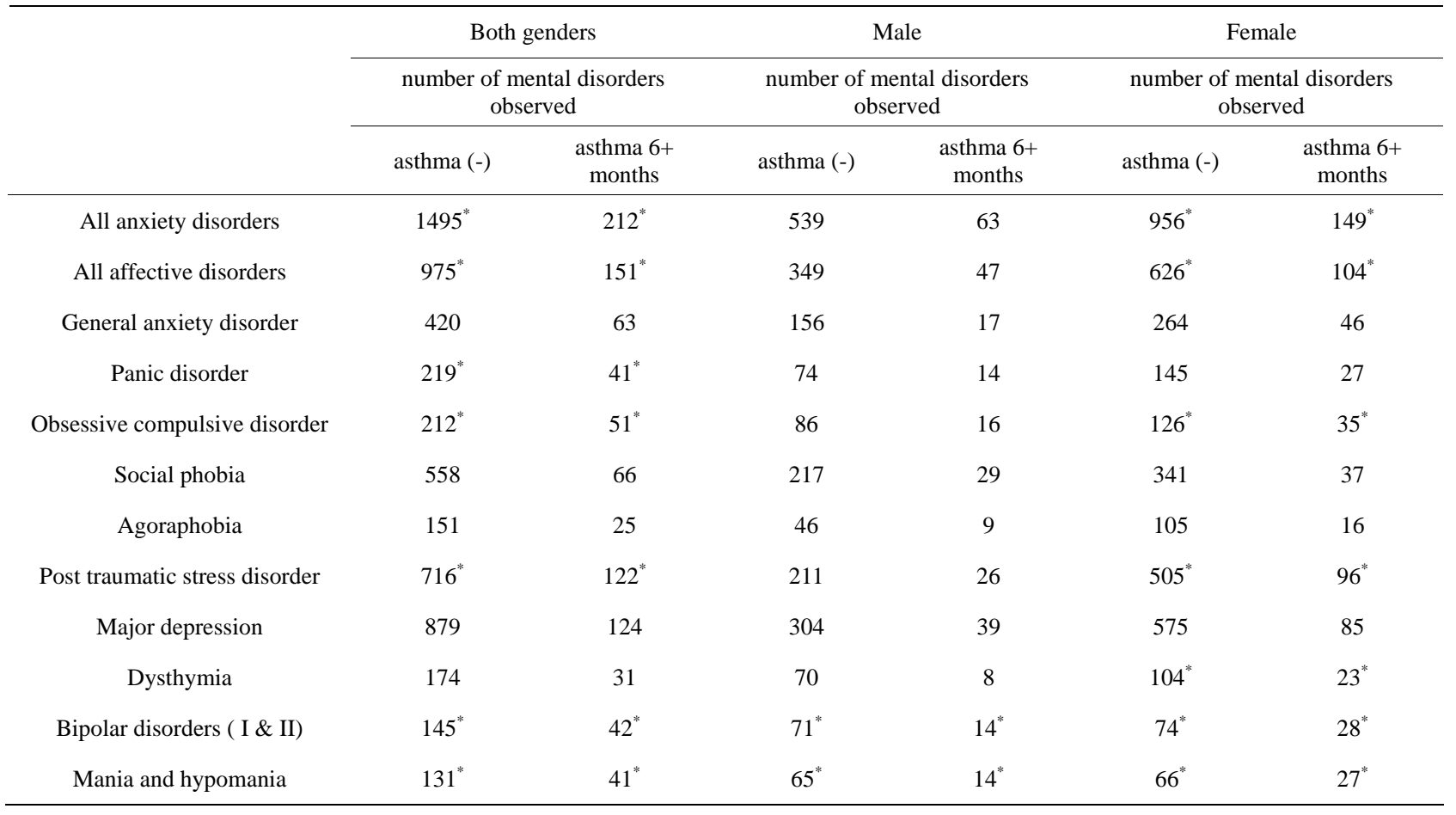

${ }^{*} \mathrm{P}$ value for log-rank tests (gender adjusted) $<0.05$.

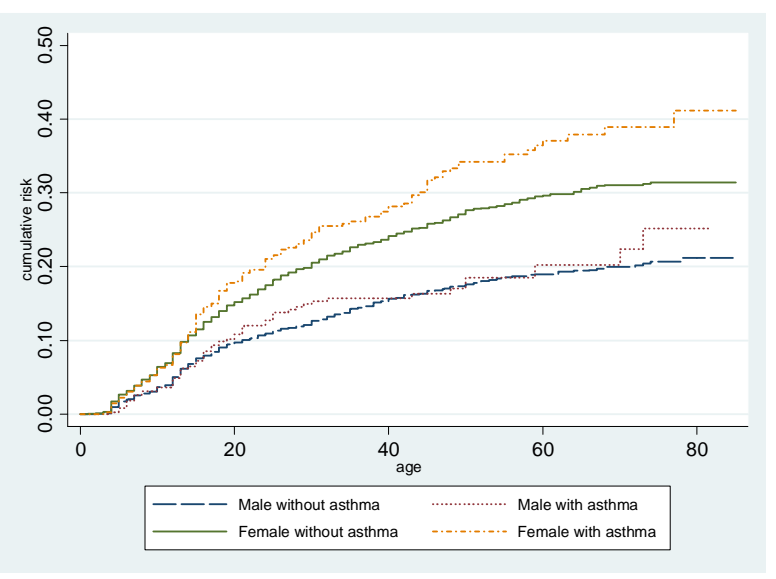

Figure 1. Gender-specific cumulative risk of anxiety disorders by asthma exposure.

nificantly higher for participants with a previous history of asthma that lasted at least 6 months among females but not males. For these subtypes of mental disorders, gender variations for the effects of pre-existing asthma were further invested with Kaplan-Meier failure function graphs (Figures A1-A6 in the appendix). There was a small difference in the cumulative risk between males with a previous history of asthma that lasted 6 months and those without for post-traumatic stress disorder (Figure A3) and dysthymia (Figure A5). These observations concurred with the results of separate log-rank tests per-

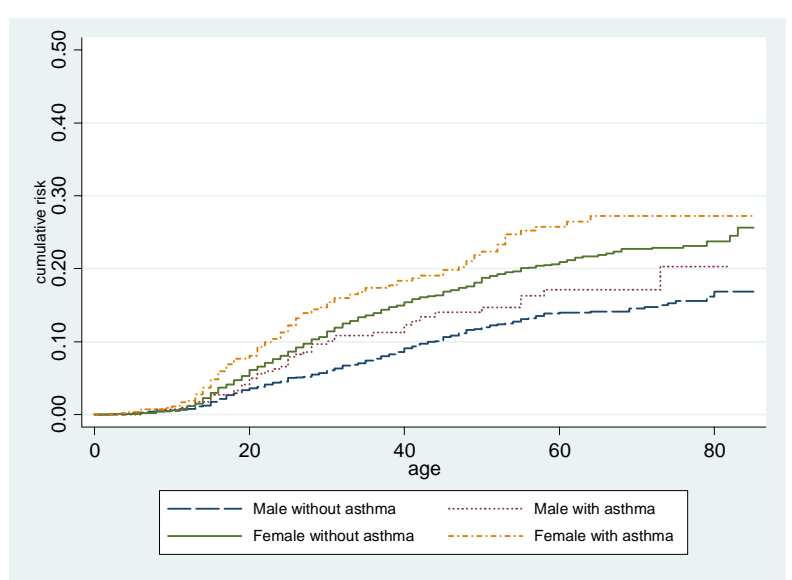

Figure 2. Gender-specific cumulative risk of affective disorders by asthma exposure.

formed by gender (Table 1).

In the multivariate analysis, a history of asthma that lasted for more than 6 months was associated with a significant increase in the risk of panic disorders, obsessive compulsive disorder, post-traumatic stress disorder, bipolar disorders, and mania and hypomania disorders after adjusting for a number of potential confounders. However, a history of asthma that lasted less than 6 months was only associated with a significant increase in the risk of post-traumatic stress disorder (Table 2).

Given that the effects of pre-existing asthma on the 
Table 2. Relative risk of anxiety disorder and affective disorder subtypes by history of asthma estimated with multivariate Poisson regression models.

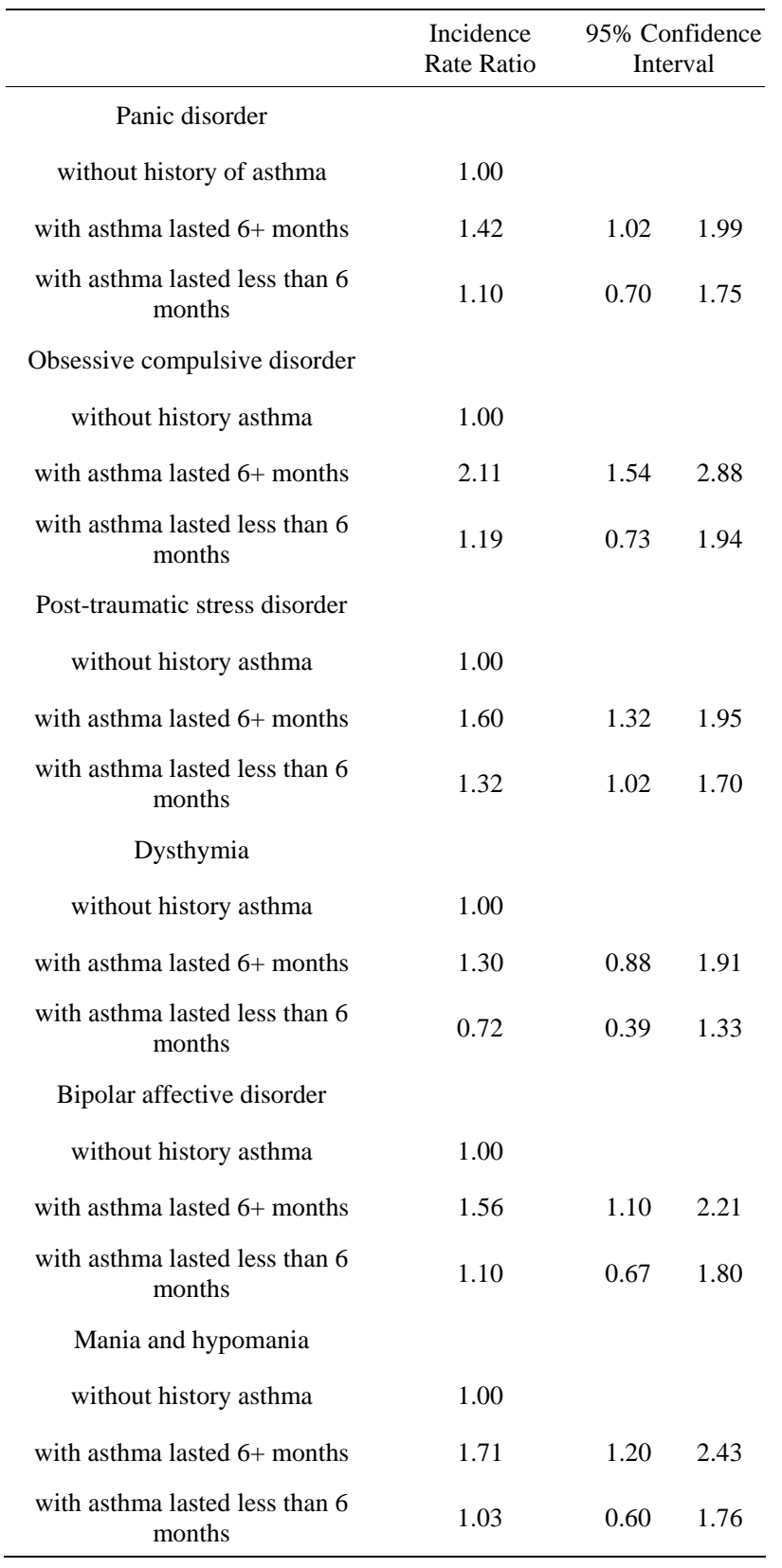

Models adjusted for gender, age at survey (adjusting for cohort effects), the age when person-years at risk were observed, whether had been started smoking daily, and pre-existence of affective disorder (when the outcome is an anxiety disorder) or pre-existence of anxiety disorder (when the outcome is an affective disorder).

cumulative risk of post-traumatic stress disorder and dysthymia varied by gender, multivariate analysis was performed for each gender separately (Table 3). A history of asthma that lasted for six months or more was associated with a significant increase in the risk of post-traumatic stress disorder only among females. There is no significant association between pre-existing asthma
Table 3. Gender-specific incidence rate ratio of post-traumatic stress disorder by history of asthma estimated with multivariate Poisson regression models.

\begin{tabular}{|c|c|c|c|c|c|c|}
\hline \multirow{3}{*}{$\begin{array}{c}\text { Post-traumatic stress } \\
\text { disorder }\end{array}$} & \multicolumn{3}{|c|}{ Male } & \multicolumn{3}{|c|}{ Female } \\
\hline & $\begin{array}{l}\text { Incidence } \\
\text { Ate Ratio }\end{array}$ & \multicolumn{2}{|c|}{$\begin{array}{c}95 \% \\
\text { Confidence } \\
\text { Interval }\end{array}$} & $\begin{array}{l}\text { Incidence } \\
\text { Rate Ratio }\end{array}$ & \multicolumn{2}{|c|}{$\begin{array}{c}95 \% \\
\text { Confidence } \\
\text { Interval }\end{array}$} \\
\hline & & & & & & \\
\hline $\begin{array}{l}\text { without history } \\
\text { asthma }\end{array}$ & 1.00 & & & 1.00 & & \\
\hline $\begin{array}{c}\text { with asthma } \\
\text { lasted } 6+\text { months }\end{array}$ & 1.29 & 0.85 & 1.95 & 1.73 & 1.39 & 2.16 \\
\hline $\begin{array}{c}\text { with asthma } \\
\text { lasted less than } 6 \\
\text { months }\end{array}$ & 1.46 & 0.90 & 2.38 & 1.28 & 0.95 & 1.74 \\
\hline \multicolumn{7}{|l|}{ Dysthymia } \\
\hline $\begin{array}{l}\text { without history } \\
\text { asthma }\end{array}$ & 1.00 & & & 1.00 & & \\
\hline $\begin{array}{l}\text { with asthma } \\
\text { lasted } 6+\text { months }\end{array}$ & 0.98 & 0.47 & 2.05 & 1.49 & 0.94 & 2.35 \\
\hline $\begin{array}{c}\text { with asthma } \\
\text { lasted less than } 6 \\
\text { months }\end{array}$ & 0.76 & 0.27 & 2.09 & 0.71 & 0.33 & 1.53 \\
\hline
\end{tabular}

Models adjusted for age at survey (adjusting for cohort effects), the age when person-years at risk were observed, whether had been started smoking daily, and pre-existence of affective disorder (when the outcome is an anxiety disorder) or pre-existence of anxiety disorder (when the outcome is an affective disorder).

and dysthymia when the analysis was performed on gender-specific subsamples.

\section{DISCUSSION}

In this study, it was observed that participants who had experienced asthma that lasted at least 6 months were at higher risk of panic disorder, obsessive compulsive disorder, post-traumatic stress disorder, bipolar disorder, and mania and hypomania. These observations are consistent with findings from previous cross-sectional studies which shown high prevalence of co-existence of asthma and certain mental disorders [3-9]. Similar findings on panic disorders were also observed in two previous prospective studies $[10,11]$. It has been well documented in experimental and clinical studies that carbon dioxide inhalation can trigger symptoms of panic disorders $[12,20,21]$, and therefore repeated exposed to increased carbon dioxide may trigger symptoms of panic disorders among asthma patients with a genetic predisposition to carbon dioxide hypersensitivity. However, the underlying causes for the observed associations between asthma and later onset of obsessive compulsive disorder and post-traumatic stress disorder are unclear. Corticosteroid therapy which is commonly prescribed to treat asthma [22] has been implicated as a potential risk factor 
for bipolar disorders, mania hypomania and depression [15,23-25]. In this study, we did not observe a significant association between asthma history and major depression, however, there were positive associations between asthma history and bipolar disorders, mania and hypomania. Bipolar disorders, mania and hypomania are much less common than major depression among the Australian population $[17,18]$, and it may be hypothesized that among asthma patients, corticosteroid therapy underlies a relatively larger proportion of mania and hypomania and bipolar disorders than depression-the latter being due to factors unrelated to corticosteroid therapy. In other words, the contribution of corticosteroid therapy to the aetiology of bipolar disorders, mania and hypomania is likely to be greater than for depression.

\section{Strengths and Limitations}

Our study has several strengths. Unlike the many crosssectional studies which inform this research domain, this study was based on a retrospective cohort, thereby allowing the order of onset of asthma and other mental health conditions to be taken into account and the direction of the association between asthma and mental disorders to be investigated. The data used in this study was collected by the 2007 Australian Mental Health and Wellbeing survey, and the survey sample is considered to represent the general Australian population [17,18]. Rather than only investigating the associations for the gendercombined sample, the associations were explored for each gender separately. To the best of our knowledge, this study is the first to show that the association between asthma history and risk of subtypes of mental disorders may differ by gender. It is a further advantage of this study that in the multivariate analysis, potential confounders including age, smoking status, pre-existing mental disorders were controlled for.

The major limitation of our study was that asthma status was not clinically diagnosed. However, we included length of time of asthma as a proxy for severity of asthma and found that for most of the mental disorders investigated, risk only increased among those participants for whom asthma lasted at least six months. This supports the notion that the self-reporting of past asthma status was relatively accurate in the MHW survey. As a retrospective study, recall bias is also a potential limitation, especially among older respondents who may have trouble remembering diagnoses over longer periods of time [26]. The findings of this study need to be confirmed in large scale longitudinal studies.

\section{CONCLUSION}

The findings of this study support the hypothesis that pre-existing asthma increases the risk of a number of anxiety disorders and affective disorders, especially among females. Predisposition to carbon dioxide hypersensitivity and corticosteroid therapy may partly explain the observed associations.

\section{REFERENCES}

[1] Eder, W., Ege, M.J. and von Mutius, E. (2006) Current concepts: The asthma epidemic. New England Journal of Medicine, 355, 2226-2235. doi:10.1056/NEJMra054308

[2] Russell, G. (2006) The childhood asthma epidemic. Thorax, 61, 276-278. doi:10.1136/thx.2005.052662

[3] Chun, T.H., Weitzen, S.H. and Fritz, G.K. (2008) The asthma/mental health nexus in a population-based sample of the United States. Chest, 134, 1176-1182. doi:10.1378/chest.08-1528

[4] Goldney, R.D., Ruffin, R., Fisher, L.J. and Wilson, D.H. (2003) Asthma symptoms associated with depression and lower quality of life: A population survey. Medical Journal of Australia, 178, 437-441.

[5] Goodwin, R.D., Faravelli, C., Rosi, S., Cosci, F., Truglia, E., de Graaf, R., et al. (2005) The epidemiology of panic disorder and agoraphobia in Europe. European Neuropsychopharmacology, 15, 435-443. doi:10.1016/j.euroneuro.2005.04.006

[6] Lavoie, K.L., Cartier, A., Labrecque, M., Bacon, S.L., Lemière, C., Malo, J.-L., et al. (2005) Are psychiatric disorders associated with worse asthma control and quality of life in asthma patients? Respiratory Medicine, 99, 1249-1257. doi:10.1016/j.rmed.2005.03.003

[7] Goodwin, R.D., Chuang, S., Simuro, N., Davies, M. and Pine, D.S. (2007) Association between lung function and mental health problems among adults in the United States: Findings from the first national health and nutrition examination survey. American Journal of Epidemiology, 165, 383-388. doi:10.1093/aje/kwk026

[8] Scott, K.M., Von Korff, M., Ormel, J., Zhang, M.-Y., Bruffaerts, R., Alonso, J., et al. (2007) Mental disorders among adults with asthma: Results from the World Mental Health Survey. General Hospital Psychiatry, 29, 123133. doi:10.1016/j.genhosppsych.2006.12.006

[9] Katon, W., Lozano, P., Russo, J., McCauley, E., Richardson, L. and Bush, T. (2007) The prevalence of DSM-IV anxiety and depressive disorders in youth with asthma compared with controls. Journal of Adolescent Health, 41, 455-463. doi:10.1016/j.jadohealth.2007.05.023

[10] Goodwin, R.D., Jacobi, F. and Thefeld, W. (2003) Mental Disorders and Asthma in the Community. Archives of General Psychiatry, 60, 1125-1130. doi:10.1001/archpsyc.60.11.1125

[11] Hasler, G., Gergen, P.J., Kleinbaum, D.G., Ajdacic, V., Gamma, A., Eich, D. et al. (2005) Asthma and Panic in young adults: A 20-year prospective community study. American Journal of Respiratory and Critical Care Medicine, 171, 1224-1230. doi:10.1164/rccm.200412-16690C

[12] Sanderson, W.C. and Wetzler, S. (1990) Five percent carbon dioxide challenge: Valid analogue and marker of 
panic disorder? Biological Psychiatry, 27, 689-701. doi:10.1016/0006-3223(90)90584-O

[13] Battaglia, M., Pesenti-Gritti, P., Medland, S.E., Ogliari, A., Tambs, K. and Spatola, C.A.M. (2009) A genetically informed study of the association between childhood separation anxiety, sensitivity to $\mathrm{CO}_{2}$, panic disorder, and the effect of childhood parental loss. Archives of General Psychiatry, 66, 64-71. doi:10.1001/archgenpsychiatry.2008.513

[14] Papp, L.A., Martinez, J.M., Klein, D.F., Coplan, J.D., Norman, R.G., Cole, R., et al. (1997) Respiratory Psychophysiology of panic disorder: Three respiratory challenges in 98 subjects. American Journal of Psychiatry, 154, 1557-1565.

[15] Brown, E.S., Khan, D.A. and Nejtek, V.A. (1999) The psychiatric side effects of corticosteroids. Annals of Allergy, Asthma \& Immunology, 83, 495-500, 503-504. doi:10.1016/S1081-1206(10)62858-X

[16] Sirois, F. (2003) Steroid psychosis: A review. General Hospital Psychiatry, 25, 27-33. doi:10.1016/S0163-8343(02)00241-4

[17] Slade, T., Johnston, A., Oakley Browne, M.A., Andrews, G. and Whiteford, H. (2009) 2007 National survey of mental health and wellbeing: Methods and key findings. Australian and New Zealand Journal of Psychiatry, 43, 594-605. doi:10.1080/00048670902970882

[18] ABS (2007) National Survey of mental health and wellbeing: Summary of results. Australian Bureau of Statistics, Canberra.

[19] Kessler, R.C., Crum, R.M., Warner, L.A., Nelson, C.B., Schulenberg, J. and Anthony, J.C. (1997) Lifetime co-occurrence of DSM-III-R alcohol abuse and depend- ence with other psychiatric disorders in the national comorbidity survey. Archives of General Psychiatry, 54, 313-321. doi:10.1001/archpsyc.1997.01830160031005

[20] Papp, L.A., Klein, D.F. and Gorman, J.M. (1993) Carbon-dioxide hypersensitivity, hyperventilation, and panic disorder. American Journal of Psychiatry, 150, 11491157.

[21] Roberson-Nay, R., Klein, D.F., Klein, R.G., Mannuzza, S., Moulton, J.L., Guardino, M., et al. (2010) Carbon dioxide hypersensitivity in separation-anxious offspring of parents with panic disorder. Biological Psychiatry, 67, 11711177.

[22] Kips, J.C. and Pauwels, R.A. (2001) Low dose inhaled corticosteroids and the prevention of death from asthma Thorax, 56, 74-78. doi:10.1016/j.biopsych.2009.12.014

[23] Wada, K., Yamada, N., Sato, T., Suzuki, H., Miki, M., Lee, Y., et al. (2001) Corticosteroid-induced psychotic and mood disorders: Diagnosis defined by DSM-IV and clinical pictures. Psychosomatics, 42, 461-466. doi:10.1176/appi.psy.42.6.461

[24] Brown, E.S. and Suppes, T. (1998) Mood symptoms during corticosteroid therapy: A review. Harvard Review of Psychiatry, 5, 239-246. doi:10.3109/10673229809000307

[25] Warrington, T.P. and Bostwick, J.M. (2006) Psychiatric adverse effects of corticosteroids. Mayo Clinic Proceedings, 81, 1361-1367. doi:10.4065/81.10.1361

[26] Kessler, R.C., Angermeyer, M., Anthony, J.C., R, D.E.G., Demyttenaere, K., Gasquet, I., et al. (2007) Lifetime prevalence and age-of-onset distributions of mental disorders in the World Health Organization's world mental health survey initiative. World Psychiatry, 6, 168-176. 


\section{APPENDIX}

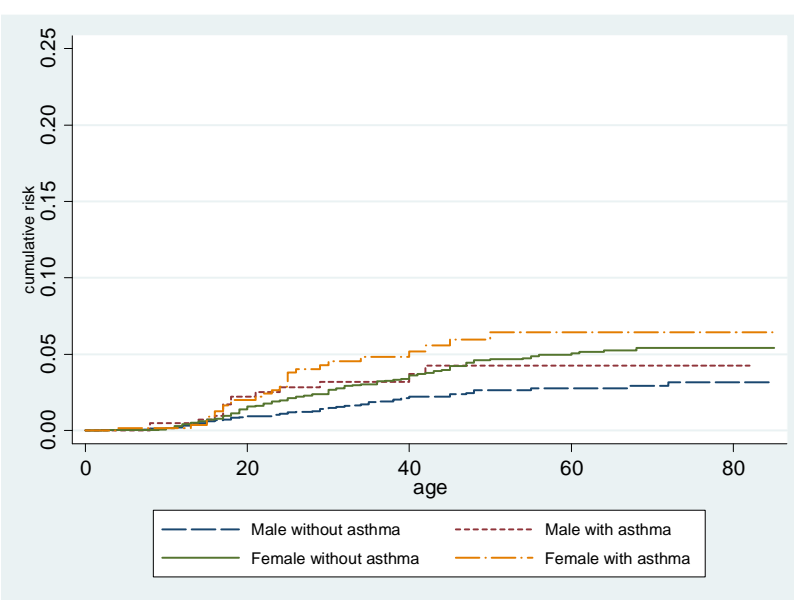

Figure A1. Gender-specific cumulative risk of panic disorder by asthma exposure.

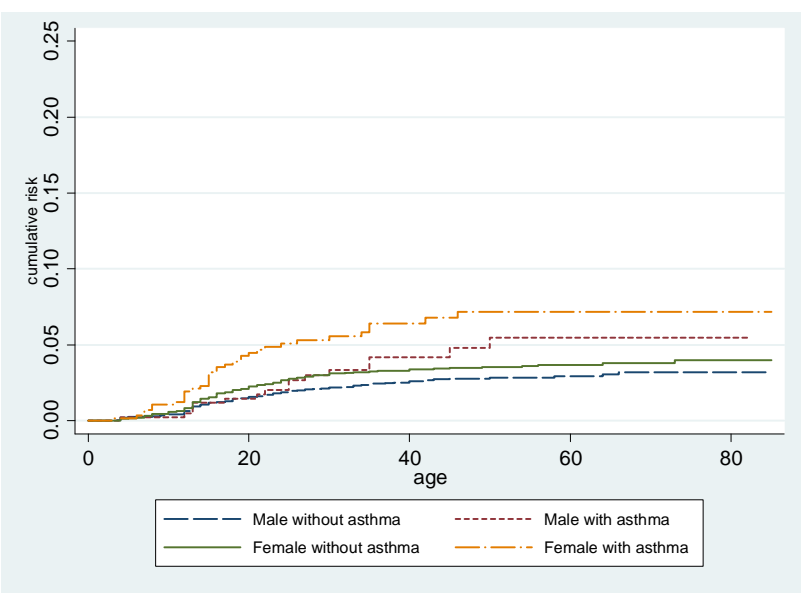

Figure A2. Gender-specific cumulative risk of obsessive compulsive disorder by asthma exposure.

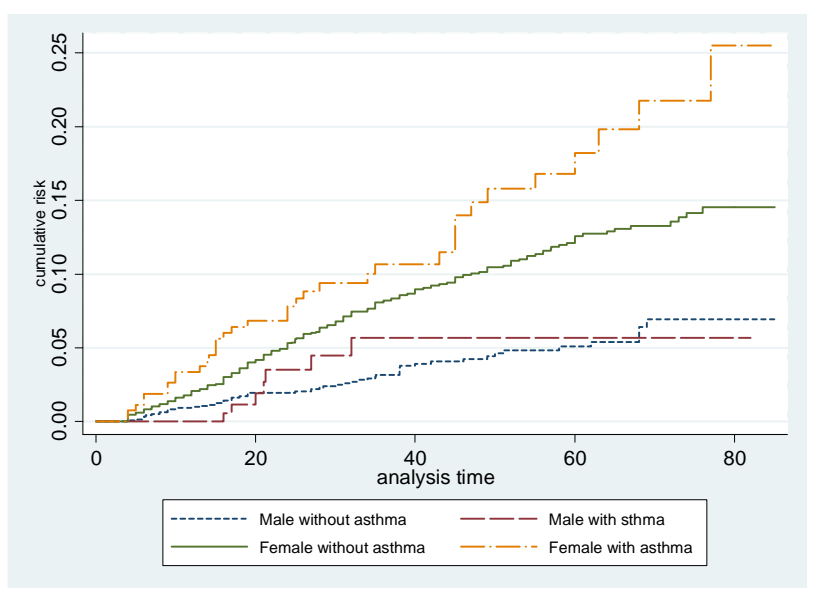

Figure A3. Gender-specific cumulative risk of post-traumatic stress disorder by asthma exposure.

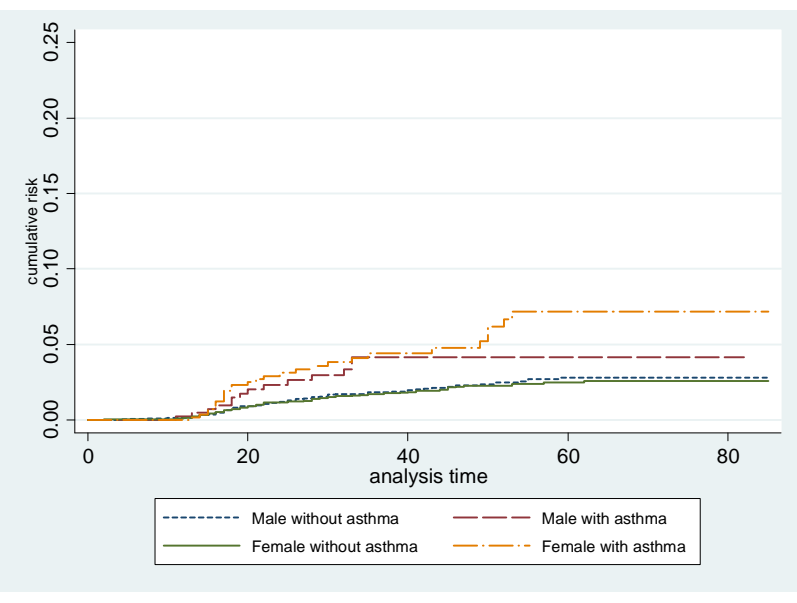

Figure A4. Gender-specific cumulative risk of bipolar affective disorder by asthma exposure.

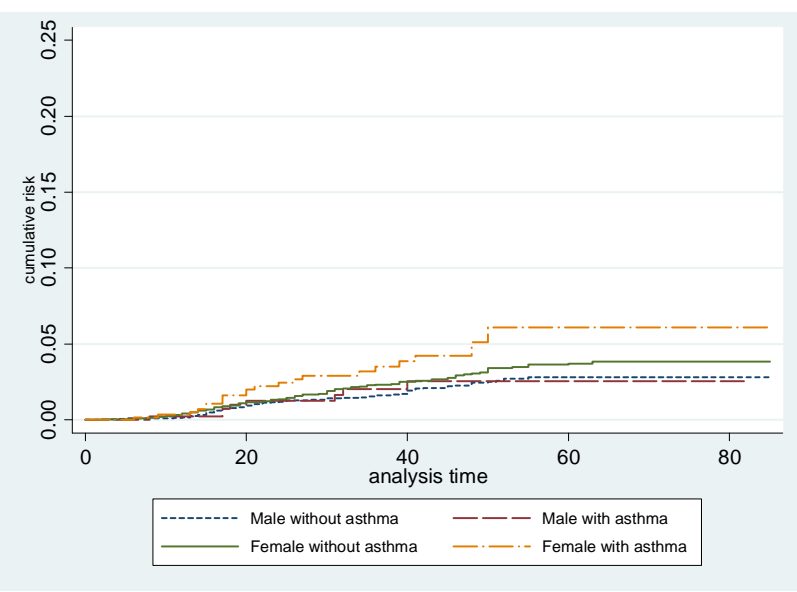

Figure A5. Gender-specific cumulative risk of dysthymia by asthma exposure.

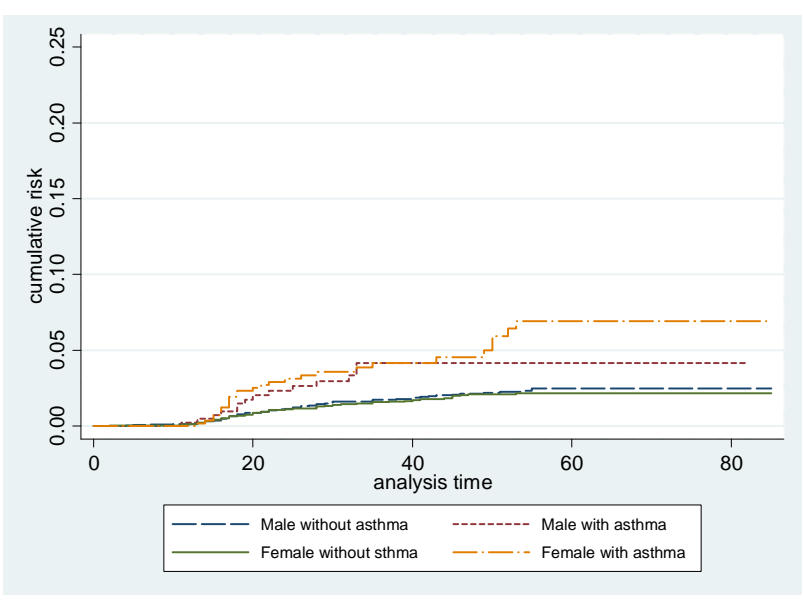

Figure A6. Gender-specific cumulative risk of mania and hypomania by asthma exposure. 